\title{
Observing and Forecasting Coastal Currents: Texas Automated Buoy System (TABS)
}

\author{
Norman L. Guinasso, Jr., Geochemical and \\ Environmental Research Group, Texas A\&M University \\ Joseph Yip, Department of Oceanography, Texas A\&M \\ University
}
Robert O. Reid, Department of Oceanography, Texas A\&M University
Leslie C. Bender, III, Geochemical and Environmental Research Group, Texas A\&M University
Matt Howard, Department of Oceanography, Texas A\&M University

Abstract: The Texas Automated Buoy System operates buoys at seven sites off the Texas coast from Brownsville to Sabine in water depths ranging from ten to one hundred meters. The system is supported by the Texas General Land Office as part of its mission to mitigate the effect of catastrophic oil spills on the Texas Coast. Buoys communicate surface currents and water temperature measured at $\mathbf{2 m}$ depth in near real time via cell phone and commercial satellite digital data links. One buoy located at East Flower Garden Banks has a $300 \mathrm{kHz}$ ADCP, a meteorology package with an ultrasonic acoustic wind velocity sensor, and a conductivity sensor.

Data are posted regularly to a web page http://www.gerg.tamu.edu/tglo and are available to the public and governments within a few hours after data collection. On the TABS web page, a graphical map presentation of TABS current vectors has links to recent data tables and historical databases. Links are also provided to other data resources for oceanographic data in the Gulf of Mexico. Also on the web page are links to an automated continental shelf forecast system that predicts currents over the Texas-Louisiana shelf on an operational basis. There are four major components in this system: (1) forecast wind field retrieving and preparation, (2) shelf circulation model module, (3) simulation plotting module and (4) web display and file transfer module. The wind field used is a 3-hour interval ETA-22 forecast gridded wind from NOAA NCEP based on 00, 06, 12, and 18UTC model runs. The shelf circulation model is a 3-D version of Princeton Ocean Model (POM) on a domain extending from the coast to a curved line extending from $25^{\circ} \mathrm{N}$ on the Mexican coast to $85^{\mathbb{R}} \mathrm{W}$ at the coastline of Florida. The operational POM model used at this time is a simplified barotropic version that permits us to reduce computational time to allow prediction of surface currents twenty-four hours into the future. The data vs. model comparison from April through December, 1999 of nine nearshore TABS buoys indicates modest skill of the model in predicting the wind driven circulation. A fully baroclinic version of TABS-POM model is undergoing tests and will be implemented on an operational basis when sufficient computational resources become available. We are also developing data-assimilating models of the whole Gulf of Mexico and beyond to couple to our shelf model to supply outer boundary conditions.

\author{
Linwood L. Lee III, Geochemical and Environmental \\ Research Group, Texas A\&M University \\ John N. Walpert, Geochemical and Environmental \\ Research Group, Texas A\&M University
}
David A. Brooks, Department of Oceanography, Texas A\&M University
Robert D. Hetland, Department of Oceanography, Texas A\&M University

Robert D. Martin, Texas General Land Office, Austin, TX

\section{INTRODUCTION}

When the supertanker Mega Borg exploded on June 6, 1990 a large quantity of oil was released into the Gulf of Mexico about 60 miles south of Galveston, TX. A climatology of ocean currents available at the time together with wind data suggested that the oil would move onshore with the winds and downcoast with the coastal currents with the ultimate impact occurring around Corpus Christi. But counter to the usual June climatology, the coastal currents were running up the Texas Coast such that oil moving toward shore was carried northeast into Louisiana waters.

The Texas General Land Office (GLO), the state agency in Texas responsible for dealing with oil spills, decided in 1994 that, to avoid the mistakes made in 1990, it would be worthwhile to place a few instrumented buoys off Texas to monitor ocean currents. The data from these buoys would be reported in near real time and could be used to make informed operational decisions in the event of an oil spill. The Geochemical and Environmental Research Group at Texas A\&M University was asked to propose a plan to install and operate the buoys. A decision was made to put together a cellular phone based telemetry system with a WHISL SeaPac 2000 current meter and mount this in an inexpensive, polyurethane foam marker buoy, manufactured by Urethane Technologies, Inc. (UTI). Woods Hole Group (WHG) delivered the first buoys in the spring of 1995, and the first buoys were deployed in April 1995. A modeling component was added in 1998. All data since inception of the program has been posted in near real time on the World Wide Web. There are now seven TGLO sponsored buoy sites in the Gulf of Mexico (Fig. 1), as well as other TABS sites sponsored by various government and industry partners

The TABS system was proved useful in 1996 during the Buffalo Barge 292 Spill (Fig. 2). A large amount of oil was spilled in the Houston Ship Channel and was blown out 
to sea by strong North winds. On March 22, 1996 it appeared that the oil was heading for the sensitive marine

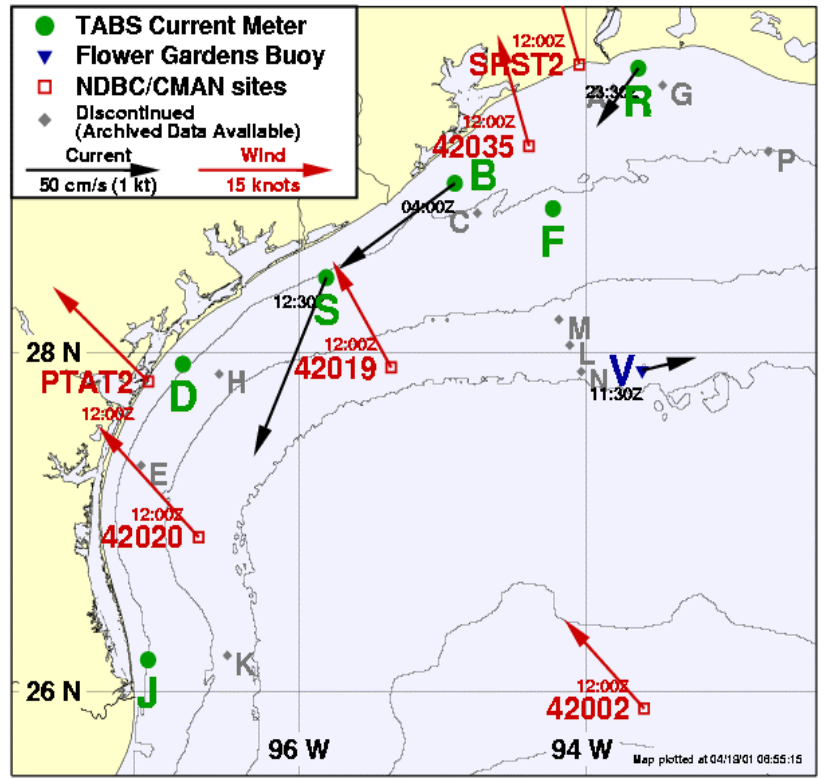

Fig.1. TABS Web page graphical interface. Red squares are NOAA buoys; green and blue symbols are TABS buoys. Clicking on symbols connects user to underlying data.

sanctuary at Sabine Pass and preparations were made to place booms around to block the oil's path. Data from the TABS buoys operating in the vicinity of the spill showed the currents had reversed on March 25, 1996. The critical time and expense (approximately $\$ 225,000$ ) of booming the Sabine Sanctuary was avoided and cleanup efforts were concentrated further down the coast. Since then TABS data has played a critical decision support role in more than a dozen offshore spills.

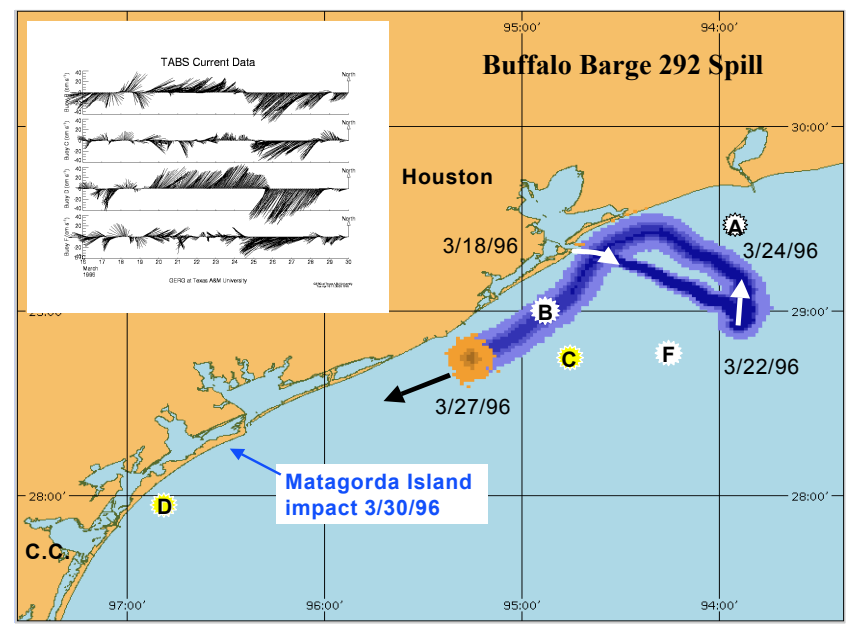

Fig. 2. Trajectory of oil and associated TABS current data is shown for the period during the Buffalo Barge 292 Oil Spill. Knowledge provided by the TABS buoys that the currents had reversed as the oil headed toward Sabine Pass enabled state oil spill planners to focus their attentions further down the coast.

\section{TABS HARDWARE AND SOFTWARE}

TABS buoys have five principal subsystems: a current meter; a cellular phone or satellite communications link; a solar-powered electrical system, a computer system and interfaces, and the buoy flotation structure $[1,2,3,4]$. Although the current sensors now in use on most TABS I buoys are single point acoustic Doppler current sensors manufactured by Aanderaa, we have deployed RD Instruments Sentinel ADCPs on several TABS II buoys in the Gulf of Mexico, and off the island of Oahu in Hawaii [5].

TABS I buoys have six, 10 watt solar panels while TABS II buoys have nine. Both use a commercially available solar panel voltage regulator system to charge internal batteries.

Woods Hole Group manufactures the computer system aboard the buoy, and Urethane Technologies, Inc. builds the buoy hulls. The assembly and wiring of the system, including the navigation light and electrical system and solar panels, is done at Texas A\&M University. By basing the design on existing products, we were able to field buoys quickly, thus providing the GLO with useful operational data within nine months of the start of the program in 1994.

The TABS II buoy was designed for operation in regions without cellular phone coverage and for water depths greater than 100m. TABS II buoys also supports additional sensors, such as Acoustic Doppler Current Profilers and meteorological sensors. TABS buoys have been deployed with Gill ultrasonic wind velocity sensors (Fig 3.).

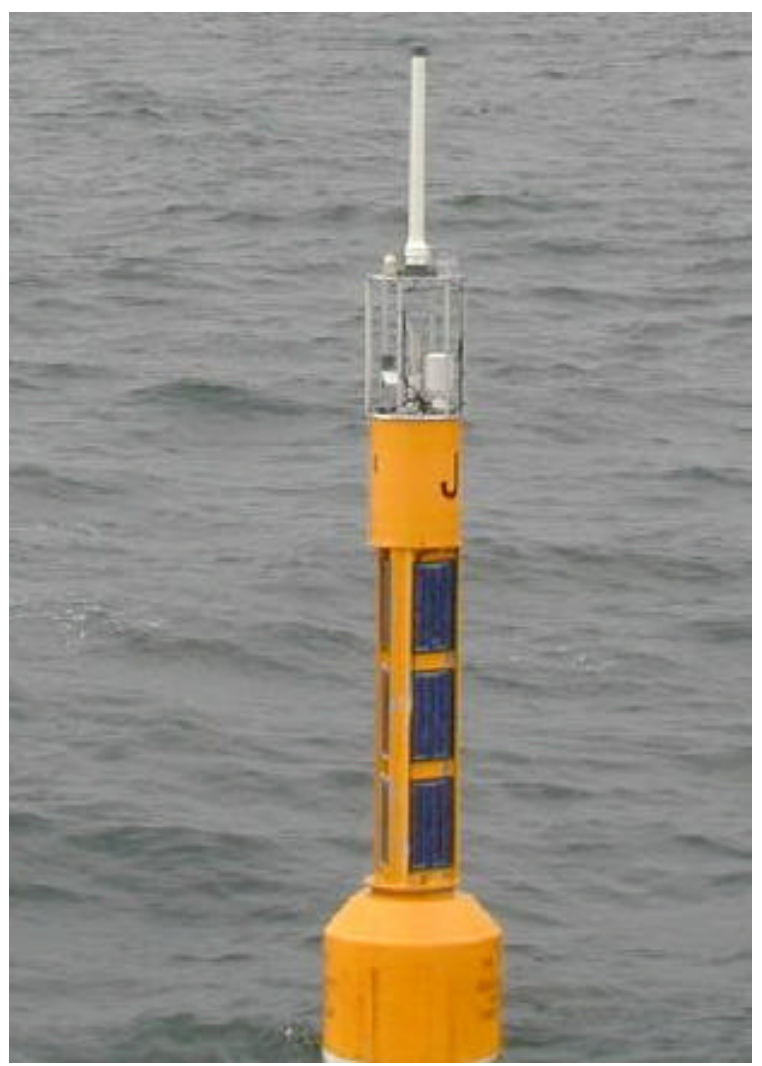

Fig. 3. TABS II Buoy at site J equipped with meteorological instrumentation to measure wind velocity components, barometric pressure and air temperature. 
Digital satellite telephone communications are now available at costs that are only slightly higher than the offshore cellular telephone service. The TABS buoys are presently using a Westinghouse Series 1000 Marine Satellite Telephone System in about a third of our buoys. The Westinghouse phone has power requirements that are within the capabilities of the solar-power system implemented on TABS II buoys and is capable of data transmission at rates up to 4800 bps.

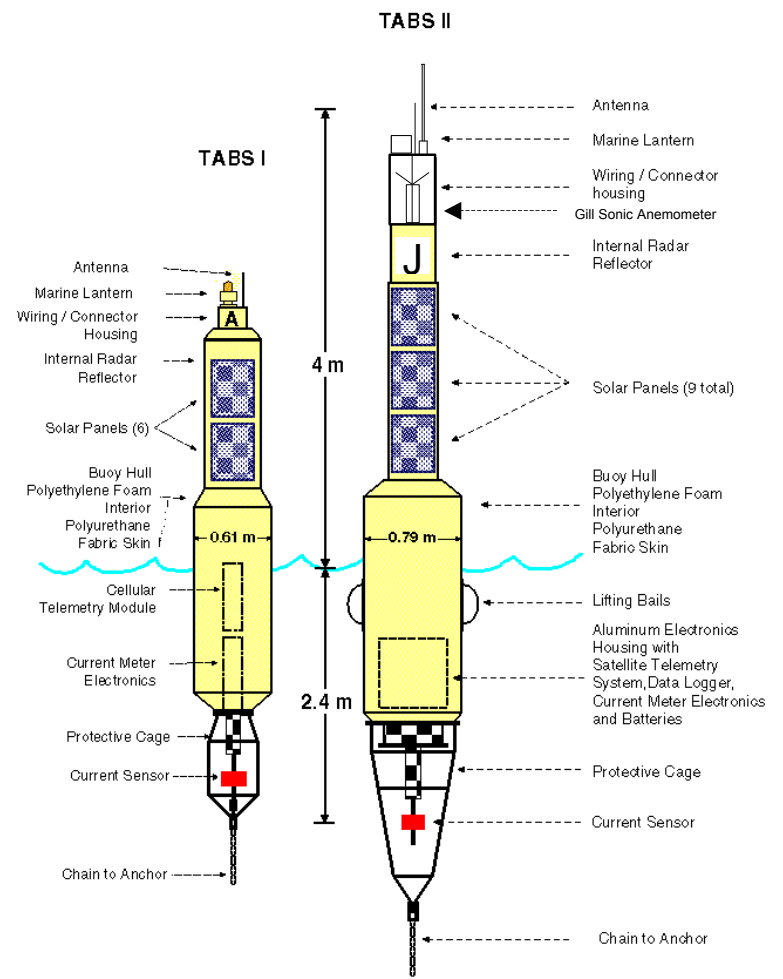

Figure 4. TABS buoys showing principal components. The TABS II buoys can also carry wind and ADCP sensors.

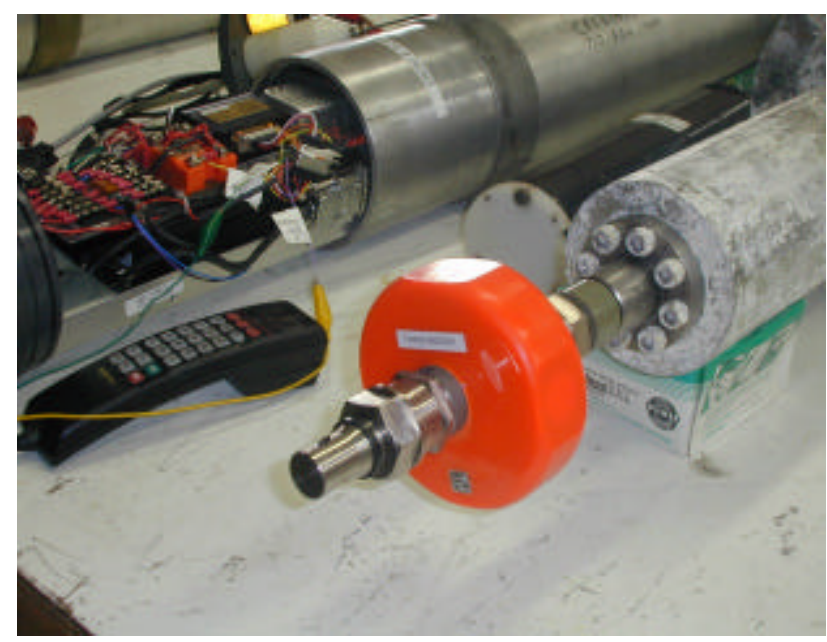

Fig. 5. Acoustic single point Doppler current meter manufactured by Aanderaa. Part of the electronics package from a TABS I buoy is shown in the background. Cellular handset is removed for deployment.
Norcom Networks (now Wireless Matrix) Corporation provides the geosynchronous satellite data-link service throughout North America, Central America, and the Gulf of Mexico. With the Norcom system, individual buoys initiate data calls directly to our computer in College Station TX via a commercial X.25 data network.

In the event of damage to the primary cellular communication system, GERG uses System Argos to provide an effective backup system for data communications. However, the effective baud rate through Argos is quite limited and the Argos satellite backup transmitter in the TABS II buoy has a limited buffer size. When using System Argos, we assure that the most recent data have priority over older data. The interval between satellite passes, the duration of a pass (elevation), and the quality of the transmission link during a pass will all vary. Since the buffer is a last-in-first-out type, some older data may be pushed out of the buffer before they can be transmitted. However, a given satellite pass will always provide the most recent buoy observations, plus several hours of past observations. Since the interval between passes will range from about 2-4 hours, some data gaps will occur.

GERG has evaluated the QualComm GSP 1620 Packet Data Modem produced by Globalstar USA and have issued a contract to Woods Hole Group to integrate this new technology into three new TABS II buoys currently under construction.

Our land-based data systems have three basic components: communication with the buoys, data analysis, and data dissemination. A Linux workstation automatically initiates calls to all of our TABS I buoys using cell phone modems, every six hours. The TABS II buoys initiate their own satellite phone call, which is received by a computer at GERG via a leased data line connected to Norcom's computer network.

\section{DATA MANAGEMENT}

The automated data collection system contains several error-checking protocols that minimize data loss and maximize data quality. No data are lost if communication with a buoy is unsuccessful for one or more scheduled calls. All data are stored in a communication buffer on board the buoy system and any gaps in the telemetry data are filled at the next successful transmission. In addition, the current meters have an independent internal data archive, which can either be accessed remotely by cellular phone or downloaded when the buoy is serviced.

Raw data received from the TABS buoys are automatically transferred to a Digital (Compaq) PW500au workstation that converts the data to engineering units and generates graphical displays. The time series plots show the currents, water temperature, buoy tilt, and various parameters that indicate the operating status of the buoy system. The data are automatically checked for any gaps, and new plots are generated on an hourly basis. Data quality is assessed visually by experienced oceanographers. An 
example of one of the data products available on the Web site is shown in Fig. 6.

The data are then inserted into a database, which facilitates extracting user specified subsets. The GLO has access to this database via FTP over the Internet. The public interface to is through the World Wide Web at http://www.gerg.tamu.edu/tglo Using their browser, the public user is able to view either the latest data, or access the database and view archived data. The user can also download the data as ASCII tables for later use. The archived data has proved useful for model initialization, model skill assessment, for operational planning purposes and for research.

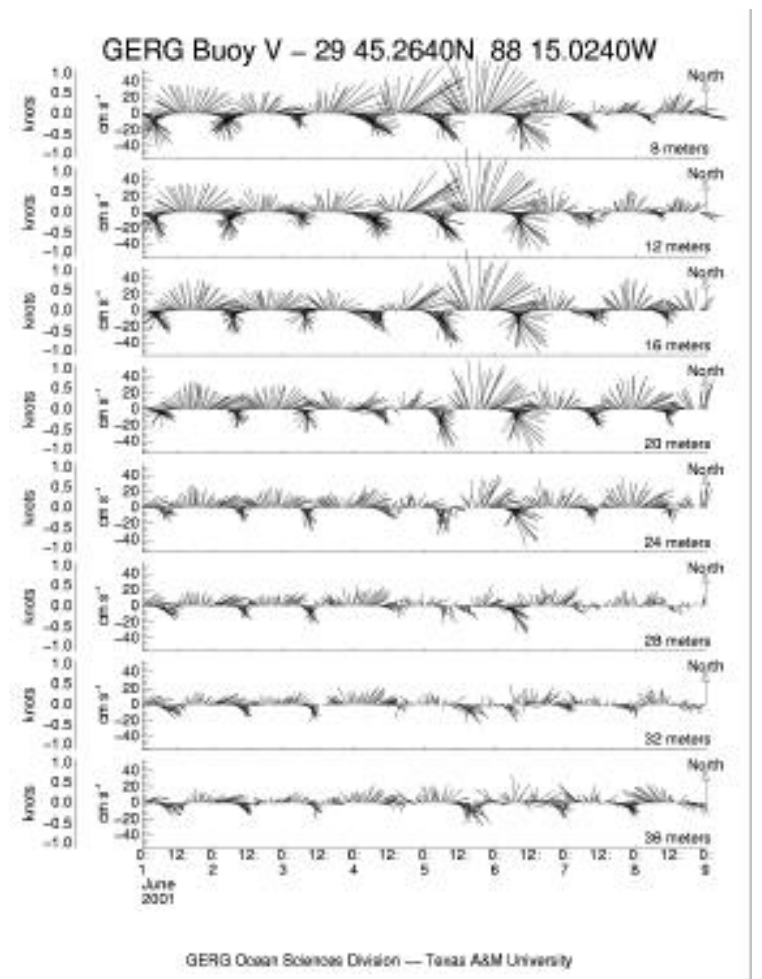

Fig. 6. Stacked stick plot of data from an ADCP current meter buoy. These data were recorded during the passage of tropical storm Allison.

In addition to our own data, we make an effort to integrate other available offshore data from the Gulf of Mexico into our web pages. For example, we display NOAA CMAN and NDBC winds and, in a manner similar to the way in which we display our ocean current data, to facilitate simultaneous analysis of both winds and currents. We also maintain active web links to the Navy's Ocean Wave model forecasts, offshore marine forecasts, harmful algal bloom reports, and predictions from the National Hurricane Center. Generally, we try to display data that we find useful for carrying out our own operations and research.

\section{MODELING}

As part of TABS, the Texas General Land Office also supports a continental shelf forecast system that predicts currents over the Texas-Louisiana shelf on an operational basis. There are four major components in this system: (1) forecast wind field retrieving and preparation, (2) shelf circulation model module, (3) simulation plotting module and (4) web display and file transfer module. The wind field used is a 3-hour interval ETA-22 forecast gridded wind from NOAA NCEP based on $00,06,12$, and $18 \mathrm{UTC}$ model runs. This wind field is extracted and archived on a regular basis from the Unidata feed to Texas A\&M University. GERG runs daily, a 3-D version of Princeton Ocean Model (POM) shelf circulation model on a domain extending from the coast to a curved line extending from $25 \mathrm{~N}$ on the Mexican coast to $85 \mathrm{~W}$ at the coastline of Florida. The operational POM model is a simplified barotropic version that permits us to reduce computational time to allow prediction of surface currents twenty-four hours into the future. The data vs. model comparison from April through December 1999 of nine nearshore TABS buoys indicates modest skill of the model in predicting the wind driven circulation. A fully baroclinic version of TABS-POM model is undergoing tests and will be implemented on an operational basis when sufficient computational resources become available. We are also developing data-assimilating models of the whole Gulf of Mexico and beyond to couple to our shelf model to supply outer boundary conditions.

\section{OPERATIONS}

At the time of this writing, GERG has funding from the state of Texas to operate seven TABS buoys in Texas coastal waters and funding from a consortium of energy companies to operate two additional buoys near Flower Garden Banks National Marine Sanctuary. In 2001 the Naval Oceanographic Office has supported two buoys in Mississippi waters as part of the Northern Gulf Littoral Initiative and two buoys near Oahu, Hawaii in support of the Ehime Maru salvage operations.

Buoys generally are left in the field for a period of 6 months or until they are damaged by collision with a vessel operating in the area. During service trips, buoys are most often replaced rather than trying to repair them at sea.
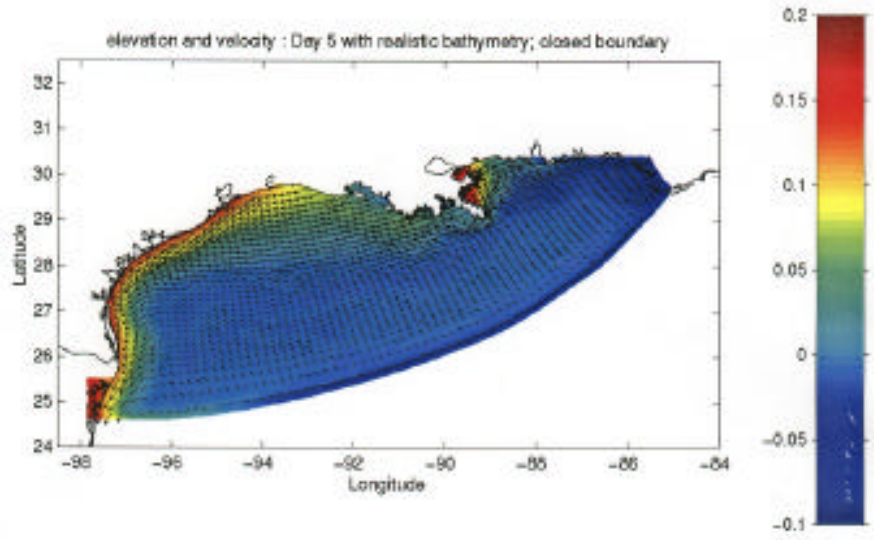

Fig. 7. Model output from a test run of the Princeton Ocean Model showing the calculation grid, sea surface elevation, and current vectors. Output from all of our models is available through our web pages. 
The most common form of damage is the breaking of communication antennas most likely caused by recreational boaters tying off to the buoys or through collision with a large vessel. Buoys have also been run down by ships and cut free of their moorings by commercial fishermen and geophysical operators. Most buoys that are set free wash up on a beach and are recovered. Recovery is most often accomplished through the use of the System ARGOS location messages.

Significant costs of operation include personnel for buoy preparation and maintenance, personnel for data system and web page operation, data communications costs, travel and ship time for buoy deployment and recovery, and hardware for replacing damaged equipment. Part of our support pays for testing and deploying new sensors.

\section{FUTURE PLANS}

We hope to use our buoys as focal points for other in situ oceanographic measurements, particularly for light, nutrients, particles, harmful algal blooms, and dissolved oxygen. We envision that our buoys will relay information in real time from sensors located nearby on the sea floor and in the water column. Data from these other sensors will be transmitted through the water column by acoustic modems or hardwire fiber optic links. We hope to have such systems installed at Flower Garden Banks within the next 12 to 18 months and at other offshore sites in the Gulf of Mexico with the next two years.

\section{Acknowledgements}

We thank Mr. Minhchau Hung $\mathrm{Vu}$ and Dr. Bruce Magnell of Woods Whole Group for their continuing efforts in developing buoy hardware and software. Mr. Frank Kelly contributed to design and original configuration of our buoys from the inception of the program in 1994. Mr. Bob Albers and Mr. Paul Clark deserve special mention for their good humor in facing many vexing buoy situations.

\section{References}

Chaplin, G.F. and F.J. Kelly, 1995: "Surface Current Measurement Network Using Cellular Telephone Telemetry". Proceedings of the IEEE $5^{\text {th }}$ Working Conference on Current Measurement. Feb 7-9, 1995, St. Petersburg, Fl.

[2] Martin, R. A., F. J. Kelly, Linwood L. Lee III, and Norman L. Guinasso, Jr., 1997: Texas Automated Buoy System: Real-time currents for oil spill response. Proceedings of the 1997 International Oil Spill Conference, April 7-10, 1997, Fort Lauderdale, FL.

[3] Kelly, F.J., N.L. Guinasso, Jr., L.L. Lee III, G.F. Chaplin, B.A. Magnell, and R.D. Martin, Jr., 1998: Texas Automated Buoy System (TABS): A public resource. Proceedings of the Oceanology International 98 Exhibition and Conference, 10-13 March 1998, Brighton UK, Vol. 1, pp. 103-112.
[4] Magnell, B.A., F.J. Kelly, and R.A. Arthur, 1998: A new telemetering environmental buoy for offshore applications. Proceedings of the Oceanology International 98 Exhibition and Conference, 10-13 March 1998, Brighton UK, Vol. 1, pp. 179-197.

[5] Walpert, J.N., N.L. Guinasso, Jr., L.L. Lee III, F.J. Kelly, 2000: Inter-comparison and Evaluation of a Single-Point Acoustic Doppler Current Sensor Mounted on a TABS II Spar Buoy. Proceedings from MTS/IEEE Oceans 2000 Conference, September 11-14, 2000, Providence, RI. 